Brazilian Journal of Forensic Sciences, Medical Law and Bioethics

Journal homepage: www.ipebj.com.br/forensicjournal

\title{
Uso de Nanopartículas Superparamagnéticas na Revelação de Impressões Dígito-Papilares Latentes
}

\author{
Use of Superparamagnetic Nanoparticles in the Development of Latent \\ Fingerprints \\ Ulisses Condomitti ${ }^{1, *}$, Eder Cavalcante ${ }^{1}$, Pedro Pacheco², \\ Alceu Totti Silveira Junior ${ }^{3}$, Henrique Eisi Toma ${ }^{3}$ \\ ${ }^{1}$ Equipe de Perícias Criminalísticas de Barueri, Superintendência de Polícia Técnico-Científica, \\ São Paulo, SP, Brasil \\ 2 Escola Técnica Estadual, Carapicuíba, SP, Brasil \\ 3 Instituto de Química, Universidade de são Paulo, São Paulo, SP, Brasil \\ * Corresponding author. E-mail: ulissescondomitti@gmail.comr. Phone: +55-11-997467602
}

Received 27 February 2020

Resumo. As impressões dígito-papilares constituem um vestígio morfológico de extrema importância em um local de crime, visto que, em função de suas características particulares, permitem a identificação de autoria do delito que gerou a força motriz da investigação pericial. Embora existam diversas técnicas para revelação e levantamento de impressões dígitopapilares latentes, o aprimoramento e atualização dessas técnicas pode subsidiar metodologias mais versáteis, que permitam maximizar a abrangência e potencializar o uso de instrumentação de campo para busca desse tipo de vestígio. Nesse artigo, demonstramos que nanopartículas superparamagnéticas constituídas por Magnetita podem ser empregadas, com auxílio de um aplicador dotado de magneto em sua extremidade (Pincel magnético) para revelação de impressões dígito-papilares, com qualidade semelhante à obtida empregando-se pó comercial preto (Sirchie) baseado em limalhas de ferro metálico, permitindo vantagens em termos de processamento e custo.

Palavras-Chave: Digitais; Magnetita; Nanopartículas; Nanopó; Forense.

Abstract. Digit-papillary impressions constitute an extremely important morphological traces in a crime scene, since, due to their particular characteristics, they allow the identification of authorship of the crime that generated the driving force of expert investigation. Although there 
are several techniques for developing and lifting latent finger-papillary fingerprints, the improvement and updating of these techniques can support more versatile methodologies that allow maximizing the scope and enhancing the use of field instrumentation to search for this type of trace. In this paper, we demonstrate that magnetite superparamagnetic nanoparticles can be employed with the aid of a magnet-tipped applicator, (Magnetic brush) for developing finger-papillary impressions, with similar quality to that obtained using commercial black powder (Sirchie) based on metallic iron filings, allowing further advantages in terms of cost and processing.

Keywords: Digital; Magnetite; Nanoparticles; Nanopowder; Forensics.

\section{Introdução}

O desenho formado em uma superfície, após contato com os dedos, é chamado de impressão digito-papilar, e está relacionado com o relevo superficial, devido às papilas dérmicas, saliências de natureza neurovascular, situadas na parte externa da derme e observáveis na epiderme ${ }^{1}$.

A associação entre impressões dígito-papilares e a identidade de um indivíduo é muito mais antiga do que se imagina. Por exemplo, a evidência mais antiga que se tem sobre a marca deixada pelos dedos foi encontrada na cidade de Jericó (Cisjordânia), onde impressões digitais eram colocadas em tijolos neolíticos datados de 7000 a.C., ainda que, na época, não existisse uma metodologia comparativa das impressões que pudesse ser empregada na identificação exata do indivíduo que a produziu, servindo apenas como uma espécie de marca registrada do fabricante ${ }^{2}$. Entretanto, a aplicação forense das impressões dígito-papilares se popularizou após a atuação de Juan Vucetich no esclarecimento de um homicídio de duas crianças, perpetrado por sua mãe, em 1892, na cidade de Necochea, Argentina².

No século XX, a utilização forense de tal vestígio morfológico se acentuou; entretanto, as técnicas evoluíram pouco desde então, normalmente (Embora não se limitando) sendo utilizadas extensivamente técnicas de revelação com cianoacrilato, ninhidrina, vapor de iodo e uso de pós, sendo que este approach possui grande predileção entre peritos criminais, devido à sua versatilidade e facilidade prática de utilização em locais de crime; entretanto, cabe a cada perito, de acordo com seu equipamento disponível, treinamento e, especialmente, características do local, a escolha do método mais adequado ${ }^{3}$. Dessa forma, é imprescindível o desenvolvimento de novas formulações de pós para revelação de impressões dígito- 
papilares latentes, como já vem acontecendo na literatura com uso, por exemplo, de Chalconas sintéticas ${ }^{4}$ e de compostos luminógenos ${ }^{5}$, sendo que o emprego de nanopartículas para tal finalidade pode representar um ganho de qualidade e eficiência para esse tipo de técnica de revelação.

A nanotecnologia lida com a matéria de dimensões entre 1 e 100 nanômetros $^{6}$; materiais nessa escala de tamanho podem apresentar propriedades distintas das convencionais em tamanho macroscópico, como uma baixíssima resistência elétrica, cores diferentes, pontos de fusão mais baixos, propriedades catalíticas superiores ou comportamento magnético diferenciado. Essas propriedades são originárias, em partes, da enorme área superficial apresentada por sistemas nanométricos. Por exemplo, uma nanopartícula superparamagnética, quando submetida a um campo magnético, alinha seu momento magnético de maneira a minimizar a energia; porém, ao se retirar o campo, flutuações térmicas excitam a partícula a estados intermediários de maiores energias entre as posições de energia mínima, tornando a alinhar-se assim que o campo é reposto. O tempo de relaxação em alguns sistemas pode ser da ordem de $10^{-9}$ e $10^{-10} \mathrm{~s}^{7}$. Dessa forma, uma partícula em estado superparamagnético não mantém magnetismo residual apreciável quando o campo é retirado; esse princípio pode ser empregado, na criminalística, para se obter pós com características magnéticas, que podem ser empregados com pincel magnético, podendo ser utilizados para revelação de impressões dígito-papilares latentes que se encontram depositadas sobre superfícies metálicas (Por exemplo, latarias de veículos), sem problema de adesão magnética do pó à superfície de maneira indiscriminada. Adicionalmente, a grande área superficial do nanomaterial pode diminuir a quantidade de pó empregado e melhorar a resolução de linhas características de impressões reveladas.

Esse trabalho propõe o estudo de nanopartículas superparamagnéticas de Magnetita $\left(\mathrm{Fe}_{3} \mathrm{O}_{4}\right)$ como pó para revelação de impressões dígito-papilares latentes sobre folhas de papel sulfite, com aplicação através de pincel magnético comercial.

\section{Materiais e métodos}

\subsection{Síntese das nanopartículas}

As nanopartículas de Magnetita foram sintetizadas através do método da coprecipitação, que permite a obtenção de óxidos metálicos que adotam a estrutura do espinélio invertido. Nesse método, o material de interesse é preparado através da 
reação entre dois sais contendo os metais de interesse nos estados de oxidação adequados. A reação ocorre em meio básico e atmosfera inerte, em meio aquoso, sendo o oxigênio previamente removido do meio reacional e apresenta vantagens como o controle sobre o tamanho e forma que pode ser obtido mediante ajuste das condições reacionais, como tipo do ânion que compõe o sal utilizado, da razão molar entre as espécies de ferro $\left(\mathrm{Fe}^{3+} / \mathrm{Fe}^{2+}\right)$, da temperatura, do $\mathrm{pH}$ e da força iônica do meio ${ }^{8}$.

A reação de co-precipitação pode ser representada conforme a Eq. 1:

$$
\mathrm{Fe}^{2+}+2 \mathrm{Fe}^{3+}+8 \mathrm{OH}^{-} \longrightarrow \mathrm{Fe}_{3} \mathrm{O}_{4}+4 \mathrm{H}_{2} \mathrm{O}
$$

Equação 1. Reação de síntese de nanopartículas de Magnetita através da técnica de coprecipitação.

Foram dissolvidos, em $400 \mathrm{~mL}$ de água ultrapura, previamente desaerada através de borbulhamento de nitrogênio, 16,8 g de $\mathrm{FeCl}_{2}$ e 23,3 g de $\mathrm{FeCl}_{3}$; a solução foi agitada em um balão de $1000 \mathrm{~mL}$ de 2 bocas durante 2 minutos sendo adicionada

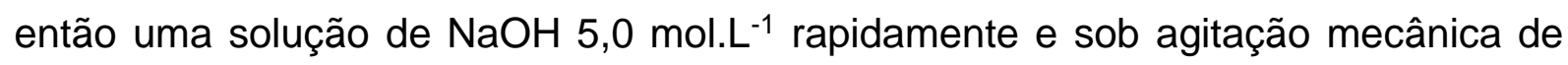
1000 RPM, até que se se observa uma mudança para coloração preta. Após quarenta minutos de agitação em atmosfera inerte, o crescimento das partículas foi interrompido com adição de Hidróxido de tetrametilamônio para formar cargas superficiais sobre o material, sendo as partículas separadas magneticamente e lavadas três vezes com etanol.

A caracterização das nanopartículas se deu através de fluorescência de raios X, através de espectrômetro de raios X Shimadzu, modelo EDX-720 empregando alvo de $\mathrm{Rh}$, janela de Be e detector de $\mathrm{Si}(\mathrm{Li})$ e efetuando-se varredura com energia variando entre $5 \mathrm{keV}$ e $9 \mathrm{keV}$, metodologia tipicamente empregada para esse composto $^{9,10}$.

O espectro de fluorescência de raios $X$, obtido nas condições analíticas descritas, pode ser observado na Figura 1. Na figura, é possível observar picos referentes à radiação $\mathrm{K} \alpha$ e $\mathrm{K} \beta$ provenientes dos átomos de Ferro que compõe majoritariamente a nanopartícula. Destaca-se, ainda, a ausência de picos de radiação relacionados a outros metais, comprovando a alta pureza das nanopartículas superparamagnéticas. 


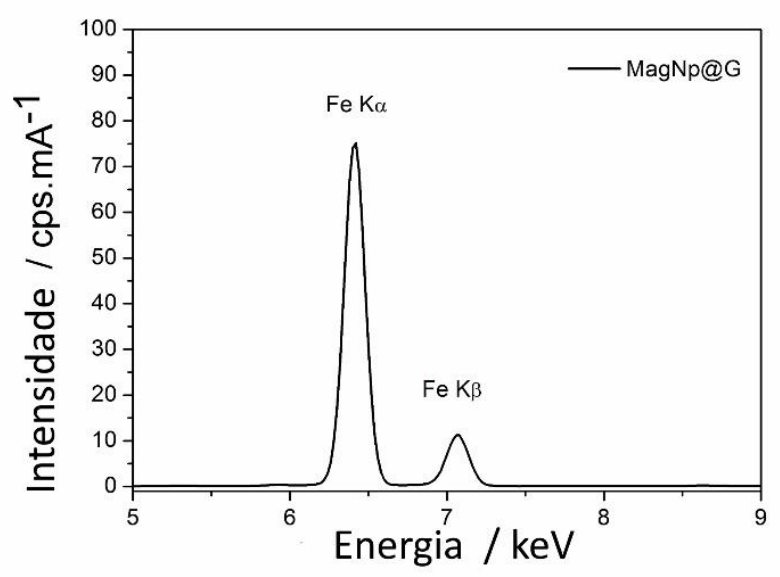

Figura 1. Espectro de fluorescência de raios-X para as nanopartículas superparamagnéticas.

Também foi realizado um estudo através de espalhamento dinâmico de luz (DLS) das nanopartículas suspensas em água destilada, em equipamento Nanotrac 252, da Nanotrac, onde foi obtido o histograma de distribuição de tamanhos representado na fig. 2 , sendo claramente visível que a maior parte das nanopartículas possuem diâmetro de $26 \mathrm{~nm}$ :

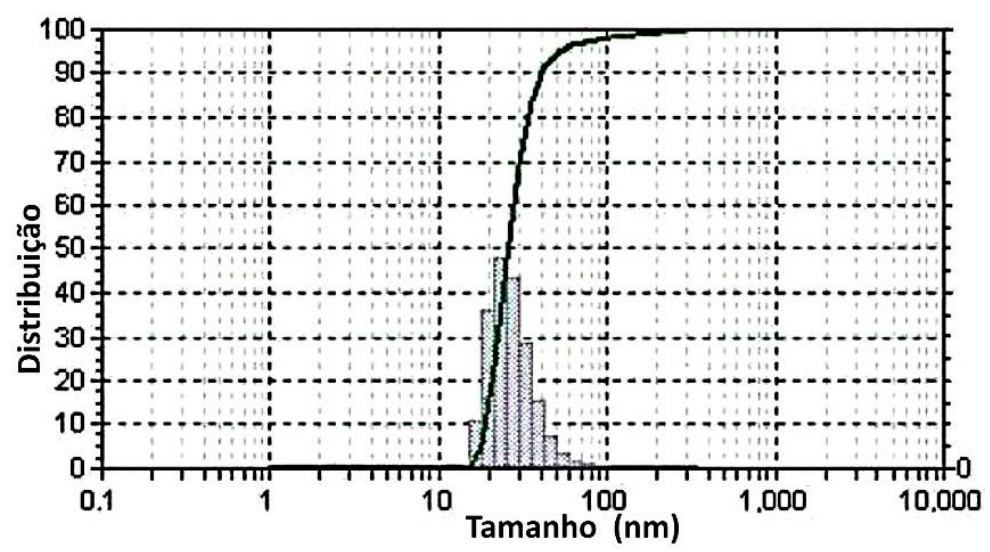

Figura 2. Histograma de distribuição de tamanho das nanopartículas de Magnetita.

\subsection{Deposição e revelação das impressões dígito-papilares}

As impressões dígito-papilares foram depositadas empregando-se a metodologia descrita a seguir.

Uma folha de papel sulfite branco, em tamanho A4, recém-removida de embalagem selada, foi posicionada, através de manipulação com uso de luvas de látex, em uma superfície perfeitamente plana, constituída por madeira. Sobre essa folha, foi pressionado o polegar da mão direita por 10 vezes, posicionado 
paralelamente à superfície, após secagem em papel toalha para remoção de excesso de oleosidade. As amostras foram coletadas em quadruplicata, empregando quatro folhas diferentes e novas de papel sulfite, manipulado nas mesmas condições já descritas.

Metade das folhas foi submetida à revelação com emprego de pó magnético comercial, marca Sirchie, sendo a outra metade submetida então à revelação empregando as nanopartículas de magnetita, aplicadas com mesmo pincel magnético (Após passar por limpeza mecânica).

\subsection{Registro fotográfico das impressões reveladas}

As impressões depositadas e reveladas, conforme exposto previamente, foram registradas fotograficamente com uso de câmera Nikon D 700, empregando os seguintes parâmetros: ISO:200, f:32, velocidade do obturador:125. Foi utilizada uma lente objetiva de $60 \mathrm{~mm}$ macro Nikon e um filtro polarizador na lente. A montagem fez ainda uso de dois flashes externos de $100 \mathrm{~W}$ (f.22), posicionados a 45 graus da superfície de papel, cuja luz foi polarizada através de uso de polarizadores, sendo utilizado ainda um refletor parabólico como modificador de luz.

Após a captura das imagens, estas foram salvas em arquivo com extensão .RAW, que passaram por procedimento de aplicação de nitidez de entrada, para corrigir os efeitos dos filtros Low pass sobre o sensor da câmera. Os arquivos foram posteriormente salvos com extensão .Tif, compensados em 1.EV, correção necessária pelo uso de filtro polarizador na câmera. Não houve manipulação digital nos arquivos ou alteração de qualquer forma por software.

\section{Resultados e discussão}

Para melhor ilustração do estudo, embora tenham sido obtidas diversas impressões, foram escolhidas as duas impressões dígito-papilares que, após a revelação e processamento fotográfico, apresentaram a melhor qualidade, que se encontram nas Figuras 3-6.

A comparação das impressões reveladas mostrou que aquelas cuja revelação foi empregado nanopó se mostram com excelente nitidez. Quando comparável à observada quando se empregou o pó magnético comercial Sirchie. As cristas papilares se mostram de forma clara e precisa, com dimensões e formato extremamente semelhantes aos observados na revelação com pó comercial. Os 
sulcos papilares, da mesma forma, se mostraram nítidos e isentos de contaminação visível por nanopartículas. Dessa forma, foram escolhidos 4 pontos característicos ${ }^{2}$ nas impressões coletadas e reveladas, sendo igualmente notáveis, através da observação cuidadosa os referidos pontos ( 1 haste, 1 ponto, 1 extremidade de linha e 1 bifurcação) nas impressões reveladas com ambos os materiais. A Figura 7 ilustra os pontos característicos e sua correspondência nas revelações:

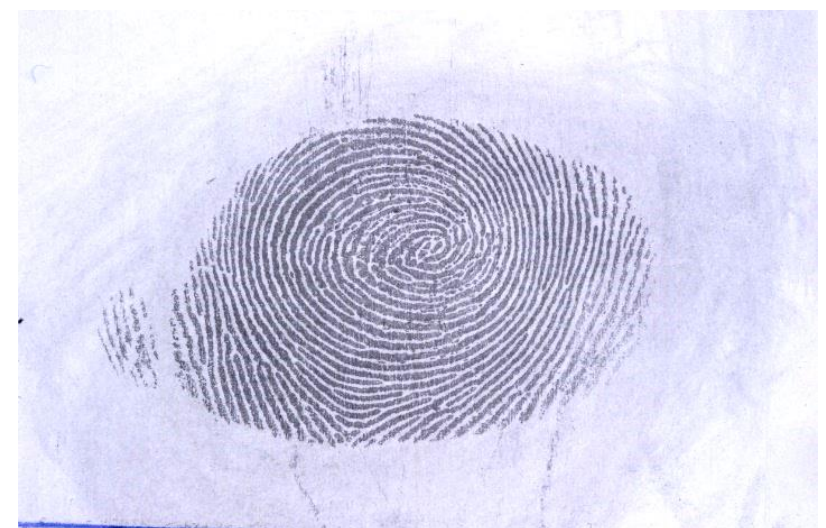

Figura 3. Impressão dígito-papilar revelada com pó comercial Sirchie (Amostra A).

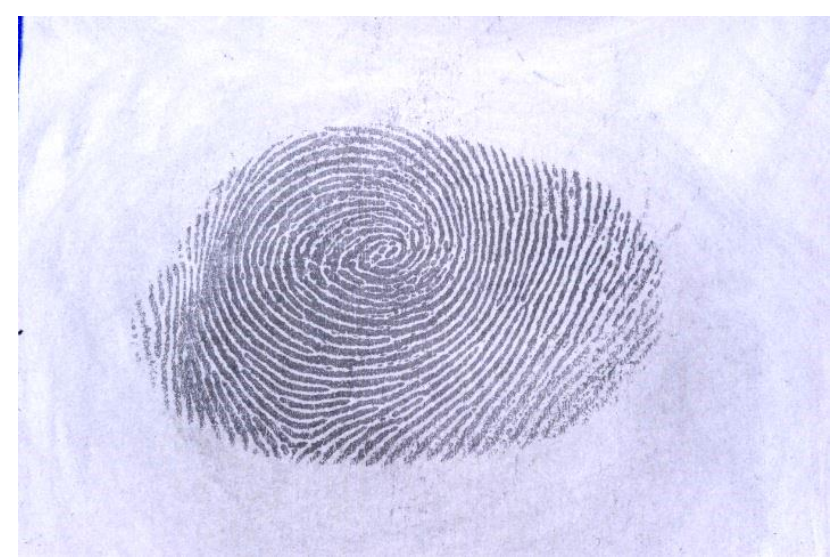

Figura 4. Impressão dígito-papilar revelada com pó comercial Sirchie (Amostra B).

Figura 5. Impressão dígito-papilar revelada com nanopó (Amostra A). 


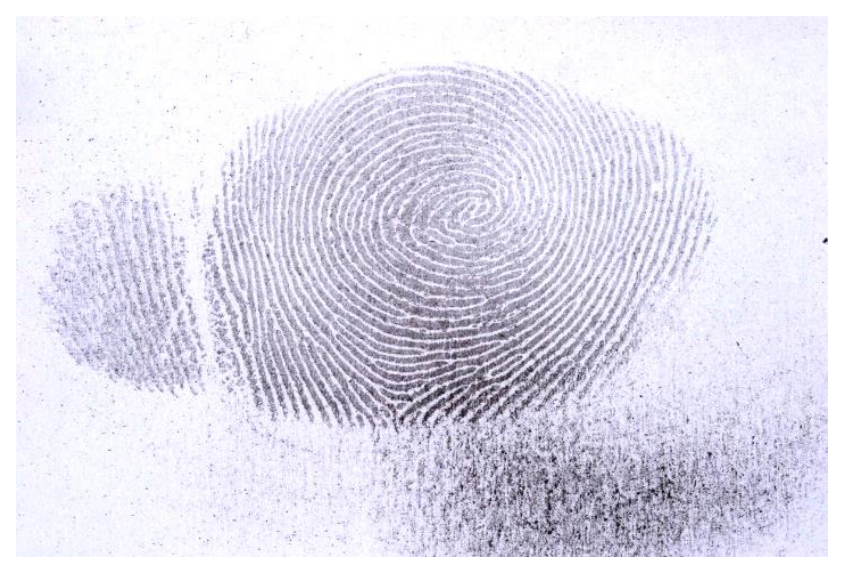

Figura 6. Impressão dígito-papilar revelada com nanopó (Amostra B).

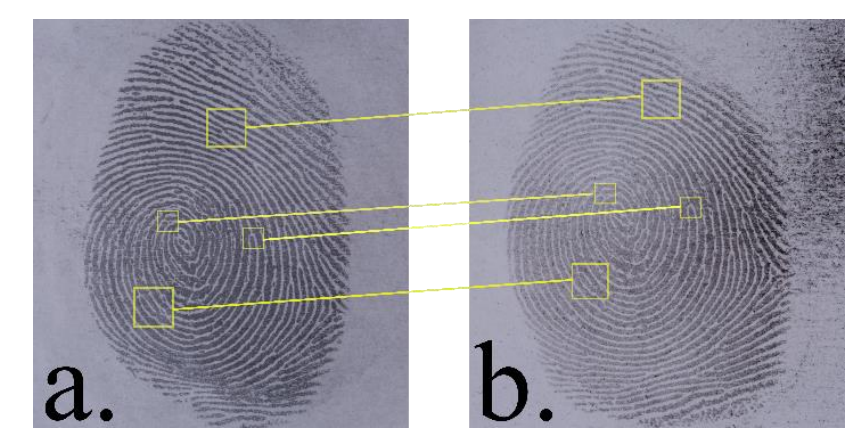

Figura 7. Imagem comparativa entre impressões dígito-papilares reveladas com: a. pó magnético comercial e b. nanopó. Os quatro pontos característicos escolhidos (Haste, ponto, extremidade de linha e bifurcação) são igualmente visíveis e identificáveis nas duas revelações.

Apenas em relação ao contraste, o nanomaterial apresentou ligeira desvantagem aparente, possivelmente pelo menor acúmulo de partículas sobre as impressões. Esse fato pode ser explicado pela maior atração magnética observada, no momento das aplicações, existente entre o pincel magnético e as nanopartículas, em comparação ao pó comercial, de forma que essa força pode atuar no sentido de impedir a liberação de nanopartículas para a superfície. Entretanto, os resultados apresentados foram interessantes por demonstrar a potencialidade do uso das nanopartículas, competindo com os agentes comerciais. Um aperfeiçoamento importante foi a mudança na forma de aplicação, substituindo o pincel magnético por um imã comercial de $\mathrm{Fe}_{14} \mathrm{Nd}_{2} \mathrm{~B}$, aplicado no verso do papel ou superfície a ser analisada. $O$ deslocamento do imã na parte de baixo promove o arraste do pó sobre a impressão digital, sem qualquer contacto com a mesma, formando imagens de alto contraste, que podem ser controladas em função da quantidade de material aplicado.

No futuro, as nanopartículas de magnetita poderão ser funcionalizadas com moléculas hidrofóbicas como ácido oleico ou esteárico, para aumentar a 
compatibilidade com o material orgânico presente nas impressões digitais. Além disso, essa estratégia poderá permitir análises ao nível microscópico da impressão dígito-papilar, por meio da espectroscopia Raman, com base nos espectros vibracionais associados ao óxido de ferro e suas interações com o material orgânico ao redor. Dessa forma serão geradas imagens hiperespectrais das impressões digitais, para trabalhos mais avançados em relação à simples inspeção visual. São perspectivas interessantes voltadas para a área da Nanoforênsica, a qual vem despontando como uma grande potencialidade a ser explorada no futuro.

\section{Conclusão}

Esse estudo demonstrou a possibilidade de formulação de um pó revelador de impressões dígito-papilares latentes através do uso de nanopartículas de magnetita. O referido nanopó, que pode ser aplicado mediante uso de pincel magnético, apresentou grande potencial de uso em campo, apresentando rendimento e qualidade de revelação similares a um pó magnético comercial Sirchie.

Estudos posteriores estão sendo iniciados para investigar melhorias no nanopó através da modificação superficial das nanopartículas e explorar novas aplicações nanotecnológicas.

\section{Referências}

1. Araújo CJA, Morais JAP. Técnicas de papiloscopia. Brasília: Secretaria nacional de segurança pública; 2007.

2. Figini ARL. Datiloscopia e revelação de impressões digitais. Campinas: Ed. Millennium; 2012.

3. Saferstein R. Fingerprints in_Ciminalisticsc: Na introduction to forensic sciences, 10 ed. New Jersey: Pearson Prentice Haal; 2007.

4. Balsan JD, Rosa BN, Pereira CMP, Santos CMM. Desenvolvimento de metodologia de revelação de impressão digital latente com chalconas. Quím. Nov. 2019; 42 (8): https://doi.org/10.21577/0100-4042.20170399

5. Qiu Z, Hao B, Wang Z, Xie N, Kam JWY, Hao H, Tang BZ. A general dusting method for latente fingerprint development based on AIEgens. Science China Chemistry. 2018; 61: 966-970. https://doi.org/10.1007/s11426-018-9280-1

6. Toma HE. O Mundo Nanométrico. São Paulo: Oficina de textos; 2004.

7. Cullity BD. Introduction to Magnetic Materials. Massachusetts: Addison-Wesley Publishing Co., Reading; 1972. 
8. Willner I, Katz I. Controlling chemical reactivity at solid-solution interfaces by means of hydrophobic magnetic nanoparticles. Langmuir. 2006; 22: 1409-1419. https://doi.org/10.1021/la052551e

9. Condomitti U, Zuin A, Novak MA, ARAKI K, Toma HE. Magnetic coupled electrochemistry: Exploring the use of superparamagnetic nanoparticles for capturing, transporting and concentrating trace amounts of analytes. Electrochemistry Communications. 2010; 13: 7274 https://doi.org/10.1016/j.elecom.2010.11.016

10. Condomitti U. Desenvolvimento de métodos magnetoeletroquímicos para sensoriamento, remediação ambiental e nanohidrometalurgia magnética. Tese de doutorado, Instituto de Química, USP; 2012. 